\title{
Hypertension in non-insulin dependent diabetes mellitus and its management
}

\author{
Michael D. Feher
}

\section{Department of Clinical Pharmacology and Therapeutics, Charing Cross \& Westminster Medical School, London SWIP 2AP, UK}

\section{Importance of hypertension}

Hypertension appears to be critically important in diabetes mellitus, not only because of its increased prevalence, but also because it accelerates both the macrovascular and the microvascular complications of diabetes. Macrovascular disease, manifested as coronary heart disease (CHD), peripheral vascular disease and cerebrovascular disease, is the major cause of morbidity in non-insulin-dependent diabetes mellitus (NIDDM) and accounts for $49-75 \%$ of the mortality in these patients. ${ }^{1}$ While most diabetic complications occur in association with hypertension, ${ }^{2,3}$ the absence of hypertension is the usual finding in the long term survivors of diabetes. ${ }^{4}$

\section{Macrovascular disease}

As the control of hyperglycaemia alone in diabetes has not reduced the incidence of macrovascular disease, ${ }^{2}$ other risk factors, including hypertension, may be the important determinants of long term outcome in these patients. From the 18 year follow-up in the Framingham study, diabetic subjects with modest elevations of blood pressure (BP) (systolic BP of $150 \mathrm{mmHg}$ ) had an increased risk of cardiovascular disease compared to subjects without glucose intolerance. ${ }^{5}$

Evidence from across populations has identified hypertension, after age, to be the most significant risk factor for CHD in the diabetic subject, ${ }^{3,6}$ an association confirmed by several prospective studies ${ }^{7-9}$ Peripheral vascular disease incidence is greatly increased in diabetes, with hypertension again being an associated factor. ${ }^{10}$

Stroke occurs 2-6 times more frequently in the diabetic compared to the non-diabetic patient, with a doubling of the frequency in the hypertensive compared to the normotensive diabetic population. ${ }^{11}$ In contrast to the general population, there are no completed long term randomized control

Correspondence: M.D. Feher, M.B., B.S., M.R.C.P. trials assessing the effects of blood pressure reduction on cardiovascular disease in a diabetic population.

\section{Microvascular disease}

Hypertension is not only an important risk factor for macrovascular, but also for the microvascular complication of diabetes. Retinopathy rates double when the systolic BP exceeds $145 \mathrm{mmHg}{ }^{12}$ Nephropathy progresses with increasing levels of arterial pressure. ${ }^{13}$ The risk of nephropathy increases three-fold when there is a family history of hypertension. ${ }^{14}$ The presence of proteinuria in the diabetic is associated with increased rates of cardiovascular morbidity and mortality. ${ }^{15}$ Persistent (Albustix negative) microalbuminuria may herald the onset of nephropathy in about one quarter of subjects with NIDDM and a greater number with insulin dependent diabetes mellitus. ${ }^{15,16}$ Of importance is the increase in blood pressure, although not in a conventional 'hypertensive' range. ${ }^{16}$ Microalbuminuria, in combination with marginally elevated $\mathrm{BP}$, and a decreased creatinine clearance are major predictors of diabetic nephropathy and early mortality. ${ }^{15,16}$

While persistent microalbuminuria may last 15 years or more before overt nephropathy develops, ${ }^{15}$ factors other than strict glycaemic control may also determine outcome. ${ }^{14}$ These include the level of BP, ${ }^{15,16}$ genetic tendency of hypertension,,$^{14}$ dietary protein intake ${ }^{17}$ and racial susceptibility. ${ }^{18}$ Once persistent proteinuria develops, BP rather than the adequacy of glycaemic control is the major determinant of the time interval before onset of both renal failure and proliferative retinopathy. ${ }^{19}$ In this situation diastolic BP is usually sustained at a level above $90 \mathrm{mmHg} .^{15,16}$ It is of interest to note that elevated albumin excretion rates are also a feature of essential hypertension in a non-diabetic population, but usually at higher levels of BP. ${ }^{20}$

\section{Overall mortality}

Co-existent hypertension and NIDDM is associated with 4-5 times the all cause mortality rate of subjects without both conditions. ${ }^{1,2,21-24}$ Evidence 
of an increased risk of death from CHD in hypertensive compared to normotensive subjects with NIDDM can be seen in cohort and insurance studies ${ }^{21-23}$ and in the study of 371 diabetic subjects by Dupree and Meyer. ${ }^{24}$ In the Bedford Study, after adjustment for other factors such as age and obesity, hypertension was a significant predictor of CHD mortality at 10 years in subjects with impaired glucose tolerance. ${ }^{25}$ In the Whitehall Study, hypertension had a more consistent relationship to CHD mortality than did cholesterol, obesity or cigarette smoking. ${ }^{9}$

\section{Prevalence of hypertension in non-insulin dependent diabetes mellitus}

Several studies have attempted to assess the prevalence of hypertension in patients with diabetes mellitus compared with non-diabetic subjects. However, methodological problems have often made the interpretation of these difficult. The older studies suffered from poor experimental design or lack of appropriate controls, while confounding variables such as age, degree of obesity, racial group, presence or absence of nephropathy, type of diabetes and treatment were not defined in the analysis. Importantly, the methods for obtaining BP measurements were not uniform among the studies; these should have included appropriate cuff size for increased arm girth and uniformity of observer for comparisons between groups. Unlike insulin dependent diabetes mellitus (IDDM) where the relationship between diabetes and hypertension indicates the existence of established nephropathy, the prevalence and aetiology of hypertension in NIDDM has been more difficult to clearly characterize. ${ }^{26}$

While not all studies have shown an association between hypertension and diabetes, ${ }^{27}$ the balance of the evidence points to a greater than chance association. ${ }^{28-31}$ Pell and D'Alonzo found 54\% greater prevalence of hypertension in diabetic patients than in an age-, sex- and weight-matched control population. ${ }^{28}$ An elevation of $\mathrm{BP}$ in diabetic patients compared with non-diabetic control subjects has also been shown in the males and females of the Framingham study ${ }^{29}$ and also in elderly women. ${ }^{30}$ While both sexes had an increase in arterial pressure in the Framingham study with a higher level in the females, this was reported without adjustment for obesity. ${ }^{29}$ By contrast, in the Bedford Survey ${ }^{25}$ and the Whitehall Study of London male civil servants, ${ }^{9}$ systolic BP was higher in newly diagnosed and borderline, but not previously diagnosed, diabetic subjects. The recent Diabetes Intervention Study has also confirmed an excess of hypertension in newly diagnosed NIDDM. ${ }^{1}$
Confirmation of a true association of hypertension and diabetes is supported by observations made in differing populations. In a report from India the prevalence of hypertension in 1662 diabetic subjects was over three times greater than that of age- and sex-matched non-diabetic controls; ${ }^{31}$ obesity, however, was more common in the hypertensive compared to the normotensive diabetic subjects. Similar hypertension rates in the USA were shown for diabetic patients aged 20-44 years, ${ }^{32}$ but in those over 65 years the rate was only approximately $50 \%$ increased.

Further information on the frequency of hypertension in several diabetic populations has come from the World Health Organization Multinational Study of Vascular Disease in Diabetics, ${ }^{3}$ where $34 \%$ were hypertensive or on antihypertensive therapy, the proportion being greater for women $(36 \%)$ than men $(31 \%)$. The highest frequencies of hypertension occurred in Moscow and Berlin for men and Arizona for women. These differences were not related to variations in degree of obesity among the centres. More recently a study from the $\mathrm{UK}^{33}$ has shown that up to $40 \%$ of the males and $53 \%$ of the females had hypertension by the WHO criteria of having BP $>160 / 95 \mathrm{mmHg}$ or were receiving hypotensive therapy. Additional studies from the United States have shown the hypertensive prevalence was $56.8 \%$ for women and $33.9 \%$ for men with an overall crude prevalence of $42 \% .{ }^{34}$ The population based study of diabetic retinopathy by Klein ${ }^{35}$ showed that hypertension was present in $21.9 \%$ of the younger (IDDM) and $58.1 \%$ of the older (NIDDM) diabetic subjects. In East Finland, where there is a high overall rate of atherosclerotic vascular disease, nearly two thirds of the population were either previously treated for hypertension or had a BP $>160 / 95 \mathrm{mmHg}$. In the diabetics $60.6 \%$ of males and $64.1 \%$ of females were hypertensive, while for the non-diabetic agematched controls the respective figures were $31.5 \%$ and $42.0 \%$. Racial groups differ in overall prevalence of hypertension; greater frequencies being observed in black compared to white patients. ${ }^{37}$

The patient with NIDDM, in contrast to IDDM, is frequently hypertensive at diagnosis. Nearly one third of subjects with NIDDM are hypertensive at the time of diagnosis of their diabetes. ${ }^{6,22,28,30}$ The increase in BP is correlated with the increased prevalence of obesity and the advanced age that is characteristic of these patients. ${ }^{26}$ This trend in hypertension is, however, also seen in studies which have been adjusted for these variables. ${ }^{30}$ Approximately $60 \%$ of NIDDM patients more than 60 years old, are hypertensive compared to $25-30 \%$ of the non-diabetic population..$^{38}$ In older subjects and women the hypertension is often characterized by elevations of systolic rather than diastolic BP. ${ }^{30}$ 
With consideration to some of the described methodological problems in defining the study populations and ascertaining blood pressure measurements, there appears to be evidence for an increased frequency of hypertension in NIDDM; with an overall prevalence rate of 1.5-2 compared to a non-diabetic population. In general, hypertension is commonly seen in association with NIDDM, occurring with a frequency of between $30-58 \%$ within the diabetic population.

\section{Pathophysiological features of diabetic hypertension}

The majority of hypertensive diabetic subjects have 'diabetic hypertension' or essential hypertension as opposed to hypertension of a definable secondary (renal or endocrine) cause. A possible explanation for the association of hypertension and diabetes is that similar genetic and/or environmental factors predispose to each condition. An inherited link has been demonstrated in several studies. ${ }^{16,39,40}$

In contrast to IDDM, where the natural history of diabetic nephropathy and the contribution of impaired renal function to the development of raised arterial pressure is well characterized, the hypertension in NIDDM is not so well defined. Obesity, common in NIDDM, may play an important pathogenic role. ${ }^{26}$ However, elevations in BP have been observed in the absence of this factor. ${ }^{30}$

In both experimental and clinical studies comparing (normotensive and hypertensive) diabetic subjects as well as non-diabetic controls, several factors have been highlighted of possible importance in the pathogenesis of diabetic hypertension.

\section{Extracellular fluid volume expansion}

This may be a consequence of a combination of factors. Exchangeable sodium is increased by $10 \%$ in hypertensive compared to normotensive diabetic subjects. ${ }^{41}$ Plasma volume may be higher than normal even in the absence of hyperglycaemia. ${ }^{42}$ Urinary sodium excretion is impaired due to the tubular effects of insulin, ${ }^{43}$ exaggerated atrial natriuretic peptide (ANP) responses ${ }^{44}$ or decreased release of natriuretic factors. ${ }^{45}$ Further evidence for an insulin effect on sodium retention comes from the observation that a natriuresis occurs when excessive insulin dosages are reduced. ${ }^{46}$

Diabetic nephropathy may play a part in extracellular fluid volume expansion. Urinary albumin excretion is increased with higher BP but the rate of deterioration of renal function tends to be slower in NIDDM, than in IDDM. ${ }^{47}$

\section{Increased total peripheral resistance}

This may be due to a number of factors. There is evidence of altered vascular sensitivity to catecholamines ${ }^{48}$ and angiotensin II. ${ }^{49}$ These effects may also predispose to the development of nephropathy independent of an effect on BP. ${ }^{50}$ Insulin has been shown to stimulate sympathetic activity ${ }^{51}$ thereby promoting an increase in vascular tone.

Increased blood viscosity, including fibrinogen ${ }^{51}$ and decreased arterial compliance either as a consequence of glycation of proteins or atherosclerosis, ${ }^{51,52}$ may lead to a loss of elastic compliance and be a mechanism of isolated systolic hypertension in NIDDM.

Further factors contributing to the altered peripheral resistance include the decreased baroreceptor response to increases in $\mathrm{BP}^{53}$ and an effect of insulin on vascular tone. Insulin resistance may result in impaired calmodulin-dependent $\mathrm{Ca}^{++}$ ATPase producing increased intracellular calcium leading to increased vascular resistance. ${ }^{54}$

The role of insulin in the pathogenesis of diabetic hypertension may also be linked to long term complications due to the association of insulin insensitivity with the development of NIDDM $^{55}$ and hypertension ${ }^{56}$ and between hyperinsulinaemia and atherogenic factors, including hypertension. ${ }^{66}$

\section{The importance of other risk factors in the management of diabetic hypertension}

In the management of diabetic hypertension two issues merit special consideration. Firstly, the increased risk of vascular complications in diabetic hypertensives may be accounted for by the clustering of atherogenic risk factors that are commonly seen in subjects with glucose tolerance. ${ }^{57}$ Many of these factors are aetiologically linked with hypertension and, when present in combination with hypertension, have a multiplicative effect on subsequent risk of cardiovascular disease $\mathrm{e}^{58}$ (see also Bain and Dodson - this issue, pp. 922-927).

Secondly, as the incidence of macrovascular disease in the diabetic has not been decreased by the control of the hyperglycaemia alone, ${ }^{2}$ other risk factors, including hypertension, may be the key determinants of the long term outcome in these patients. Abnormalities in serum lipids and lipoproteins in diabetes mellitus have been considered in other papers in this symposium (see Winocour this issue, pp.917-921, Merrin \& Elkeles, pp. 931-937; Durrington pp. 947-952). MacFarlane has also discussed the importance of smoking in diabetes (this issue, pp. 923-930).

Both the alterations in lipids ${ }^{58-60}$ and the presence of tobacco, while contributing to vascular 
complications, may also be important variables influencing choice of therapy in the diabetic hypertensive.

\section{Obesity}

Obesity is linked to the development of hyperten$\operatorname{sion}^{59}$ and to changes in lipid metabolism, glucose tolerance and the development of NIDDM..$^{55}$ It is also associated with worsening of insulin sensitivity ${ }^{60}$ and with adverse changes in both atherogenic and thrombogenic factors. ${ }^{61,62}$ The effect of weight reduction on cardiovascular disease risk may be mediated through an improvement in these associated metabolic changes and including BP. Beta-blocker anti-hypertensive therapy, as well as precipitating diabetes, has been associated with weight gain in some individuals, ${ }^{61}$ which militates against its widespread use in the diabetic hypertensive.

\section{Fibrinogen}

Elevated fibrinogen in the non-diabetic population has been shown to be an independent risk factor for stroke $^{61}$ and coronary heart disease. ${ }^{61-64}$ This fibrinogen-related risk of macrovascular disease is further exaggerated when there is associated hypertension. ${ }^{64}$ Only a few studies in diabetic subjects have described an association of fibrinogen with microvascular ${ }^{65}$ as well as macrovascular complications. ${ }^{65,66}$

The pathophysiological significance of fibrinogen is related to its involvement in fibrin deposition, platelet aggregation and adhesion and blood viscosity ${ }^{67}$ Blood viscosity is also an important determinant of total peripheral resistance and thus of blood pressure. ${ }^{68,69}$ Increased blood viscosity has also been observed in diabetes, ${ }^{65}$ obesity and smoking. ${ }^{62,67}$

With the strong association of fibrinogen with vascular disease, the raised fibrinogen and associated rheological changes in the diabetic hypertensive could facilitate arterial wall atheroma ${ }^{67}$ The increased blood viscosity may also be the critical determinant of blood flow in a vessel previously narrowed by atheroma. Treatment of hypertension may not eliminate fibrinogendependent processes, as the changes in fibrinogen and viscosity with adrenergic blocker therapy are independent of dose and duration of the pharmacological agent used. ${ }^{69} \mathrm{~A}$ recent study in treated hypertensive subjects with NIDDM demonstrated that, despite effective blood pressure control, fibrinogen concentrations and blood viscosity were increased compared to a normotensive control group. $^{51}$

\section{Proteinuria}

Proteinuria is another risk factor for vascular disease, and is associated with elevated blood pressure, raised fibrinogen, abnormal lipid metabolism, as well as being a marker of nephropathy. Reduction in protein (albumin) excretion and delayed deterioration in renal function, due to a lowering of blood pressure has been demonstrated with most groups of antihypertensive drugs. $^{70,71}$ More recent data have shown that this reduction in albumin excretion independent of BP change can be achieved with angiotensin converting enzyme (ACE) inhibitors and calcium channel blockers. ${ }^{71}$ On the basis of current evidence there appears to be no clear benefit of selecting only ACE inhibitors over other antihypertensive drug groups in order to lower BP in diabetes.

\section{Left ventricular hypertrophy}

Left ventricular hypertrophy (LVH), a common accompaniment of raised arterial pressure, has been shown in the general population to be a more powerful cardiovascular risk factor than hypertension itself. ${ }^{72} \mathrm{~A}$ reduction of $\mathrm{LVH}$ with the use of ACE inhibitors, alpha-blockers and calcium channel blockers has been shown in short term studies in non-diabetic subjects. ${ }^{73}$ In the diabetic patient with hypertension, the cardiac effects of hypertension may be difficult to distinguish from a diabetic cardiomyopathy as both conditions may be associated with isolated diastolic left ventricular dysfunction. ${ }^{74}$ Further studies in diabetic groups are needed to examine the relationship between antihypertensive therapy, LVH and long term complications.

\section{Metabolic effects of antihypertensive drugs: implications for the treatment of diabetic hypertension}

\section{Glucose homeostasis}

The effects of antihypertensive drug therapy on glucose homeostasis have been demonstrated in both laboratory and clinical studies (Table I). Case finding in primary care demonstrated that in subjects treated for both hypertension and diabetes, it was more common for a hypertensive subject to develop diabetes than for a diabetic subject to become hypertensive. ${ }^{75}$ Several short term clinical trials have shown a worsening of glucose tolerance with thiazide diuretics and betablockers. $^{75-79}$ Prospective studies have confirmed these observations. Murphy reported a 14 year follow-up of 34 hypertensive subjects treated with thiazide antihypertensive therapy. ${ }^{77}$ An increased 
Table I Potential sites of action of antihypertensive drugs on glucose metabolism

\begin{tabular}{cl}
\hline ACE inhibitors : & $\begin{array}{l}\text { Bradykinin accumulating enhancing } \\
\text { peripheral insulin sensitivity }\end{array}$ \\
Alpha-blockers : & $\begin{array}{l}\text { (only alpha } \\
\text { insulin release) }\end{array}$ \\
Beta blockers $\quad:$ & $\begin{array}{l}\text { Diminished insulin secretion due to } \\
\text { beta-blockade } \\
\text { Unopposed alpha-inhibition of } \\
\text { insulin secretion } \\
\text { Variable alterations in glycogen and } \\
\text { somatostatin secretion }\end{array}$ \\
Calcium channel blockers \\
(Pharmacological doses) \\
Inhibit intracellular calcium influx \\
(decrease insulin release) \\
Interindividual variation in \\
susceptibility to diabetogenic \\
effects
\end{tabular}

(Therapeutic doses)

No overall effect on glycaemic control

Diuretics : Direct inhibition of insulin release Hypokalaemia

Enhanced catecholamine secretion

Enhanced catecholamine effect and phosphodiesterase inhibition

Diminished intracellular transport of glucose

In hypoglycaemia:-

Beta blockers : An effect of non-selective beta-blockade on adrenoreceptors and catecholamine responses.

incidence of diabetes was reported in hypertensive subjects compared to controls treated with cardioselective beta-blocker therapy over 9 years. ${ }^{78}$ While the effects on glucose homeostasis from these studies were small, evidence from the Whitehall Study indicates that such an effect, if continued, could have an adverse effect on cardiovascular risk. ${ }^{9}$

The use of beta-blocker therapy has induced variable alterations in glucose tolerance. ${ }^{79,80}$ This may reflect the fact that the adrenergic nervous system affects glucose regulation at several physiological sites. ${ }^{80,81} \mathrm{~A}$ recent report has shown glucose disposal (insulin resistance) to be the main mechanism influencing long term alterations in glucose tolerance in subjects treated with $\beta_{1}$ adrenergic blocking drugs. ${ }^{78}$

In vitro studies have shown that alpha ${ }_{2}$ adrenoreceptors inhibit the insulin response. ${ }^{80}$ However, in clinical trials with alpha-blocker antihypertensive therapy no major effect on

glycaemic control has been documented. ${ }^{82-84}$ In studies using the hyperinsulinaemic euglycaemic clamp technique, the $\alpha_{1}$-blocker, prazosin, improved insulin sensitivity. ${ }^{83}$ In a recent study in noninsulin dependent diabetic hypertensive subjects,

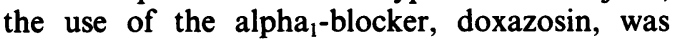
associated with a trend towards improving glycaemic control, while there was a significant deterioration with the cardio-selective beta-blocker, atenolol. ${ }^{84}$

In therapeutic doses ACE inhibitors and calcium channel blockers have no adverse effect on glucose homeostasis, but, by contrast, calcium channel blockers in pharmacological doses impair glucose tolerance. ${ }^{76}$

\section{Effects on serum lipids and lipoproteins}

The currently used groups of antihypertensive drugs, which include diuretics, alpha- and betaadrenergic blockers, centrally acting drugs, vasodilators, calcium antagonists and ACE inhibitors, differ in their effect on the lipid profile. These drugs exert separate influences on sites of production, secretion and catabolism of lipoproteins. ${ }^{85}$ The adverse effects on serum cholesterol, triglyceride and lipoproteins with diuretic antihypertensive therapy are wello documented ${ }^{85}$ Alpha-blockers have been shown to reduce total- and LDL- cholesterol and serume triglyceride and to increase HDL- cholesterol, ${ }^{84}$ while beta-blockers appear to have the opposite effect, predominantly increasing the serum triglyceride and reducing total $\mathrm{HDL}$ and $\mathrm{HDL}_{2}-$ cholesterol. ${ }^{85-87}$ This atherogenic lipid profile may correct rapidly on withdrawal of beta-blocker therapy. ${ }^{87}$ Studies with calcium antagonists and angiotensin-converting enzyme inhibitors have shown no adverse effects on the lipid profile. ${ }^{85}$

Epidemiological findings have highlighted that an abnormal lipid profile is more common in untreated and treated hypertensives compared to a normotensive population.$^{88}$ It would therefore be prudent, in order to reduce risk of cardiovascular disease, that these risk factors are considered together with the treament choices for diabetic hypertension.

\section{What level of blood pressure should be treated?}

According to the WHO technical report, ${ }^{89}$ 'hypertension' is defined when the diastolic BP exceeds $95 \mathrm{mmHg}$ and/or the systolic BP is greater than $160 \mathrm{mmHg}$. Borderline hypertension is considered to be a systolic BP exceeding $140(141-159)$ $\mathrm{mmHg}$ and a diastolic BP greater than 90 (91-94) $\mathrm{mmHg}$. The diagnosis is made after three separate consistent readings of an elevated $\mathrm{BP}$ are recorded. 
To use these criteria in order to initiate treatment for the diabetic hypertensive subject is, at present, not clearly established. However, the British Hypertension Society ${ }^{90}$ recommends that a diastolic BP $100 \mathrm{mmHg}$ or more, recorded repeatedly over 3 months, in a subject below the age of 80 years is an indication for drug treatment. It is of interest to note that the Working Party on Hypertension in Diabetes in the USA has recommended $140 / 90 \mathrm{mmHg}$ to be the intervention threshold for diabetic hypertension. ${ }^{91}$

There is now considerable evidence that hypertension increases the absolute risk of complications for the diabetic subject. However, there are few data on the reduction of this risk as a consequence of treatment. Evidence for a 'lower threshold' at which to treat diabetic hypertension compared to non-diabetic hypertension is inferred from several observations in subjects with diabetes and hypertension, particularly the overall increased mortality and rates of vascular complications as well as the synergistic effects of diabetes mellitus in combination with other risk factors on cardiovascular disease incidence.

From long term follow up studies such as the Framingham 18 year follow-up, ${ }^{5}$ cardiovascular events in subjects with glucose intolerance occur$\mathrm{red}^{92}$ at a lower level of diastolic blood pressure compared to non-diabetic subjects. When persistent proteinuria occurs, diastolic BP is usually sustained at more than $90 \mathrm{mmHg}$. A reduction in systemic arterial pressure retards the development of renal failure and reduces proteinuria.

\section{Therapeutic considerations}

The potential benefits of treatment for the diabetic hypertensive should be to reduce overall mortality, prevent cardiovascular disease and retard the progression of renal and retinal disease.

Hypertension, as discussed here and elsewhere in this symposium, is linked with several cardiovascular risk factors, including alterations in lipoproteins and the glucose-insulin axis as well as vascular changes in the form of left ventricular hypertrophy and decreased compliance in peripheral arteries. Contemporary practice, therefore, should not only be directed to lower BP but also take these issues into account.

The use of an appropriate cuff size in the measurement of BP is of critical importance for the diagnosis of hypertension as many diabetic subjects have an increased arm circumference due to obesity. Consideration should also be given to associated problems common to diabetic subjects such as; premature and/or occult coronary artery disease or peripheral vascular disease, retinopathy, peripheral and autonomic neuropathy.
Quality of life in the diabetic hypertensive has not been widely studied. The high frequency of sexual dysfunction in the diabetic male should highlight the potential contribution of antihypertensive drug therapy, in particular the thiazide diuretics and beta-blockers. ${ }^{79,91}$

To date there are no completed prospective randomized controlled trials assessing outcome of antihypertensive therapy in diabetic subjects. Decisions regarding antihypertensive therapy for the diabetic subject are often made by extrapolation from studies in the non-diabetic. Furthermore, little is known about the contribution of therapy to the severity and frequency of hypertension in the diabetic population. Therefore, antihypertensive therapy should take into consideration the metabolic and associated features of NIDDM as well as other risk factors in order to reduce complications associated with hypertension.

\section{Non-drug therapy}

Non-drug treatments of a weight-reducing diet for obesity-related hypertension and low dietary salt confer benefit. ${ }^{92}$ However, the optimal dietary recommendations for hypertensive diabetic subject remain to be clarified, as there is evidence that current recommendations may worsen insulin resistance and atherogenic lipid profile. ${ }^{93}$

Table II Some non-lipid effects of antihypertensive therapy important for the diabetic subject

ACE inhibitors :

first-dose effect

hyperkalaemia

worsening renal function (in renal artery stenosis)

proteinuria (in high doses)

cough

Alpha-blockers :

first-dose effect

Beta-blockers :

decrease in insulin sensitivity

attenuation of hypoglycaemic symptoms worsening of peripheral vascular disease impotence

weight gain

Calcium channel blockers :

flushing

headache

ankle swelling

Centrally acting drugs :

impotence

Diuretics :

decrease insulin secretion \pm sensitivity impotence

hyperuricaemia

electrolyte disturbances 


\section{Drug therapy}

Due to the high frequency of hypertension in NIDDM, drug therapy is often needed. In the assessment of pharmacological therapy many compounds appear to have disadvantages for diabetic subjects due to their action on the glucose-insulin axis, lipid metabolism and general side-effect profile discussed previously.

To date there is little evidence that, in the treatment of hypertension of diabetes, a 'steppedcare' approach (i.e. additional treatment) should be favoured. If small doses below therapeutic potential produce partial control of BP without side effects, then there is good cause for increasing only the single drug. Furthermore, many side effects of antihypertensive drugs are dose independent and occur in the absence of alterations in blood pressure ${ }^{84}$ It would therefore seem appropriate for the initial treatment to be with a single drug. An additional or second drug may reduce compliance in a subject who is often already on drug treatment for glucose control. The current wide selection of drugs should allow for individualization of the choice. Anti-hypertensive drugs with either neutral or beneficial effects on glucose homeostasis and lipid metabolism should be favoured; these include ACE inhibitors, alpha-blockers or calcium channel blockers. The use of diuretics and beta-blockers in first line drug therapy should therefore be limited (Table II). Only in poorly controlled hypertension should combination drug therapy be instituted.

\section{References}

1. Panzram, G. Mortality and survival in type 2 (non-insulindependent) diabetes mellitus. Diabetologia 1987, 30: 123-131.

2. Pyorala, K. \& Laakso, M. Microvascular disease in diabetes mellitus. In: Mann, J.I., Pyorala, K. \& Teuscher, A. (eds) Diabetes in Epidemiological Perspective. Churchill Livingstone, Edinburgh, 1983, pp. 183-247.

3. Diabetes Drafting Group. Prevalence of small vessel and large vessel disease in diabetic patients from 14 centres. The World Health Organisation multinational study of vascular disease in diabetics. Diabetologia 1985, 28: 615-640.

4. Oakley, W.G., Pyke, D.A., Tatersall, R.B. \& Watkins, P.J. Long term diabetes: a clinical study of 92 patients after $\mathbf{4 0}$ years. $Q J$ Med 1974, 43: 145-156.

5. Kannel, W.B. \& Kreger, B.E. Recent Framingham findings on morbidity and mortality in hypertension. In: Arntzenius, A.C., Dunning, A.J. \& Snellen, H.A. (eds). Blood Pressure Measurement and Systemic Hypertension. Medical World Press, Breda, Holland, 1981, pp. 103-127.

6. Vusiitupa, M., Siitonen, O., Pyorala, K. et al. The relationship of cardiovascular risk factors to the prevalence of coronary heart disease in newly diagnosed type 2 (noninsulin-dependent diabetes. Diabetologia 1985, 28: 653-659.

7. Pyorila, K., Aromaa, A.\& Reunanen, A. Hypertension and mortality in diabetic and non-diabetic Finnish men. Diabetologia 1984, 27: 322A.

8. Janka, H.U. \& Dirschedl, P. Systolic blood pressure as a predictor for cardiovascular disease in diabetes. A 5 year logitudinal study. Hypertension 1985, 7 (Suppl II): 1190-1194.

9. Fuller, J.H., Shipley, M.J., Rose, G. Jarrett, R.J. \& Keen, H. Coronary heart disease and stroke mortality by degree of glycaemia; the Whitehall study. Br Med J 1983, 287: 867-870.

10. Janka, H.V., Standl, E. \& Mehnert, H. Peripheral vascular disease in diabetes mellitus and its relation to cardiovascular risk factors; screening with the Doppler ultrasonic technique. Diabtes Care 1980, 3: 207-213.

11. Roemboldt, M.E., Palumbo, P.J., Whisnant, J.P. \& Elveback, L.R. Transient ischaemic attack and stroke in a community-based diabetic cohort. Mayo Clin Proc 1983, 58: 56-58.

12. Knowler, W.C., Bennett, P.H. \& Ballantine, E.J. Increased incidence of retinopathy in diabetics with elevated blood pressure. $N$ Engl J Med 1980, 302: 645-650.
13. Parving, H.H. Andersen, A.R., Smith, U.M., Christiansen, J.S., Oxenboll, B. \& Svendsen, P.A. Diabetic nephropathy and arterial hypertension; the effect of antihypertensive treatment. Diabetes 1983, 32 (Suppl 2): 83-87.

14. Krowlewski, A.J., Canessa, M., Warram, J.H. et al. Predisposition to hypertension and susceptibility in insulindependent diabetes mellitus. $N$ Engl J Med 1988, 318: $140-145$.

15. Consensus Statement Proceedings from the International Workshop on preventing the kidney disease of diabetes mellitus; Public Health Perspectives. Am J Kidney Dis 1989, 13: 2-6.

16. Christensen, C.K. \& Mogensen, C.E. The course of incipient diabetic nephropathy: studies of albumin excretion and blood pressure. Diabetic Med 1985, 2: 97-102.

17. Viberti, G. Interventions based on microalbuminuria screening and low-protein diet in the treatment of kidney disease of diabetes mellitus. Am J Kidney Dis 1989, 13: 41-44.

18. Cowie, C.C., Port, F.K., Wolfe, R.A., Savage, P.J., Moll, P.P. \& Hawthorne, V.M. Disputes in incidence of diabetic and end-stage renal disease according to race and type of diabetes. N Engl J Med 1989, 321: 1074-1079.

19. Hasslacher, C., Ritz, E., Terpstra, J., Gaalasch, G., Kunowski, G. \& Rall, C. Natural history of nephropathy in type 1 diabetes: relationship to metabolic control and blood pressure. Hypertension 1985, 7 (Suppl II): 74-78.

20. Parving, H.H., Jensen, H.A.E., Mogenese, C.E. \& Evrin, P.E. Increased urinary albumin-excretion rate in benign essential hypertension. Lancet 1974, i: 1190-1192.

21. Fuller, J.H. Epidemiology of hypertension associated with diabetes mellitus. Hypertension 1985, 7 (Suppl III): 11-3 11-7.

22. Gottlieb, M.S. The natural history of diabetes: factors at time of diagnosis which can be predictive of length of survival. J Chron Dis 1974, 27: 435-445.

23. Goodkin, G. Mortality factors in diabetes. J Occup Med 1975, 17: 716-721.

24. Dupree, E.A. \& Meyer, M.B. Role of risk factors in the complications of diabetes mellitus. Am J Epidemiol 1980, 112: $100-112$. 
25. Jarrett, R.J., McCartney, P. \& Keen, H. The Bedford Survey: ten year mortality rates in newly diagnosed diabetics, borderline diabetics and normoglycaemic controls and risk indices for coronary heart disease in borderline diabetics. Diabetologia 1982, 22: 79-84.

26. Drury, L. Diabetes and arterial hypertension. Diabetologia 1983, 24: 1-9.

27. Keen, H. Track, N.S. \& Sowry, G.S.C. Arterial pressure in clinically apparent diabetics. Diabete Metab 1965, 1: 159-178.

28. Pell, S. \& D'Alonzo, C.A. Some aspects of hypertension in diabetes mellitus. JAMA 1967, 202: 104-110.

29. Garcia, M.J., McNamara, P.M., Gordon, T. \& Kannell, W.B. Morbidity and mortality in diabetics in the Framingham population: sixteen year follow-up study. Diabetes 1974, 23: $105-111$.

30. Barrett-Connor, E., Criqui, M.J., Klauber, M.R. \& Holdbrook, M. Diabetes and hypertension in a community of older adults. Am J Epidemiol 1981, 113: 276-284.

31. Vaishnava, H. \& Bhasin, R.C. Hypertension in Indian diabetics. J Chron Dis 1969, 21: 691-702.

32. Horan, M.J. Diabetes and hypertension. In: National Diabetes Data Group; Diabetes in America; Diabetes Date. Compiled 1984, Chapter XVII. US Dept. Health Human Services; NIH Publication No: 85-1468; August 1985, pp. XVII-I-XVII-21.

33. Turner, R.C. UK Prospective diabetes study: prevalence of hypertension and hypotensive therapy in patients with newly diagnosed diabetes. Hypertension 1985, 7 (Suppl II): 8-13.

34. Sprafka, J.M., Bender, A.P. \& Jagger, H.G. Prevalence of hypertension and associated risk factors among diabetic individuals. The Three-City Study. Diabetes Care 1988, 1: 17-22.

35. Klein, R., Klein, B.E., Moss, S.E. \& De Mets, D.L. Blood pressure and hypertension in diabetes. Am J Epidemiol 1985, 122: $75-89$.

36. Laakso, M., Ronnemaa, T., Pyorala, K. et al. Atherosclerotic vascular disease and risk factors in non-insulindependent diabetics and non-diabetic subjects in Finland. Diabetes Care 1988, 11: 449-463.

37. Pacy, P.J., Dodson, P.M., Beevers, M., Fletcher, R.F. \& Raylor, K.G. Prevalence of hypertension in white, black and Asian diabetics in a district hospital diabetic clinic. Diabetic Med 1985, 2: 125-130.

38. Christlieb, A.R. The hypertension of diabetes. Diabetes Care 1982, 5: 50-80.

39. Krolewski, A.S., Czyzka, A., Kopezynski, J. \& Pywik, S. Prevalence of diabetes, coronary heart disease and hypertension in the families of insulin-dependent and non-insulindependent diabetics. Diabetologia 1987, 21: 520-524.

40. Kelleher, C., Kingston, S.N., Berry, D.D. et al. Hypertension in diabetic clinic parents and their siblings. Diabetologia 1988, 31: 76-81.

41. Feldt-Rasmussen, B., Mathiesen, E.R., Deckert, T et al. Central role for sodium in the pathogenesis of blood pressure changes independent of angiotensin, aldosterone and catecholamines in type 1 (insulin-dependent) diabetes mellitus. Diabetologia 1987, 30: 610-617.

42. Borchner-Mortensen, J. Glomerular filtration rate and extracellular fluid volume during normoglycemia and moderate hyperglycemia in diabetes. Scand J Clin Lab Invest 1973, 32: 311-316.

43. DeFronzo, R.A. The effect of insulin on renal sodium metabolism. Diabetologia 1981, 21: 165-171.

44. DeChatel, R., Toth, M. \& Barna, I. Exchangeable body sodium: its relationship with blood pressure and ANF in patients with diabetes mellitus. $J$ Hypertension 1986, 4 (Suppl 6): 5526-5528.

45. Sowers, J.R., Levy, J. \& Zemel, M.B. Hypertension and diabetes. Med Clin N Am 1988, 72: 1399-1414.
46. Tedde, R., Sechi, A., Marigliano, A., Pala, A. \& Scano, L. Antihypertensive effect of insulin reduction in diabetichypertensive patients. Am J Hypertens 1989, 2: 163-170.

47. Fabre, J., Balant, L.P., Dayer, P.G., Fox, H.M. \& Vernet, A.T. The kidney in maturity onset diabetes mellitus: a clinical study of 510 patients. Kidney Int 1982, 21: 730-738.

48. Weidman, P., Beretta-Piccoli, C. \& Keusch, G. Sodium volume factor, cardiovascular reactivity and hypotensive mechanisms of diuretic therapy in hypertension associated with diabetes mellitus. Am J Med 1979, 67: 779-784.

49. O'Hare, J.A., Ferriss, J.B., Twomext, B.M., Gonggrijp, H \& O'Sullivan, D.J. Changes in blood pressure, body fluids, circulating angiotensin II and aldosterone with improved diabetic control. Clin Sci 1982, 63: 4155-4185.

50. Walker, W.G., Hermann, J., Codd, T. \& Russell, R.P. Role of hypertension in diabetic renal disease. Md Med J 1988, 37: 363-367.

51. Feher, M.D., Rampling, M.W., Sever, P.S. \& Elkeles, R.S. Diabetic hypertension - the importance of fibrinogen and blood viscosity. J Hum Hypertension 1988, 2: 117-122.

52. Chien, $S$. Blood rheology in hypertension and cardiovascular disease. Cardiovasc Med 1977, 2: 356-360.

53. Eckberg, D.L., Harkins, S.W., Fritsch, J.M., Musgrave, G.E. \& Gardner, D.F. Baroreflex control of plasma norepinephrine and heart period in healthy subjects and diabetic patients. $J$ Clin Invest 1986, 73: 366-374.

54. Zemel, M.B., Bedford, B.A., Zemel, O.C., Marwah, O., Sowers, J.R. Altered caution transport in non-insulindependent diabetic hypertension: effects of dietary calcium. $J$ Hypertens 1988, 6 (Suppl 4): S228-S230.

55. Reaven, G.M. Role of insulin resistance in human disease. Diabetes 1988, 37: 1595-1607.

56. Stout, R.W. Insulin and atheroma - an update. Lancet 1987 , i: $1077-1079$.

57. Zavaroni, U., Dall'aglio, E., Bonora, E., Alpi, O., Passari, M. \& Reaver, G.M. Evidence that multiple risk factors for coronary artery disease exist in persons with abnormal glucose tolerance. Am J Med 1987, 83: 609-612.

58. Kannel, W.B. \& McGee, D.L. Diabetes and glucose tolerance as risk factors for cardiovascular disease: The Framingham Study. Diabetes Care 1979, 2: 120-126.

59. Krieger, D.R. \& Landsberg, L. Mechanisms in obesityrelated hypertension: role of insulin and catecholamines. Am J Hypertens 1988, 1: 84-90.

60. Pollare, T., Lithell, H., Selinus, I. \& Berne, C. Sensitivity to insulin during treatment with atenolol and metoprolol: a randomised double-blind study of effects on carbohydrate and lipoprotein metabolism in hypertensive patients. $\mathrm{Br}$ Med J 1989, 298: 1152-1157.

61. Wilhelmsen, L., Svardsudd, K., Korsan-Bengtsen, K., Larsson, B., Welin, L. \& Tibblin, G. Fibrinogen as a risk factor for stroke and myocardial infarction. N Engl J Med 1984, 311: $501-505$.

62. Meade, T.W., Brozovic, M., Chakrabarti, R.R. et al. Haemostatic function and ischaemic heart disease: principal results of the Northwich Park Heart Study. Lancet 1986, ii: 533-537.

63. Yarnell, J.W.G., Sweetnam, P.M., Elwood, P.C. et al. Haemostatic factors and ischaemic heart disease - the Caerphilly study. Br Heart J 1985, 53: 483-487.

64. Stone, M.C. \& Thorp, J.M. Plasma fibrinogen - a major coronary risk factor. J $R$ Coll Gen Pract 1985, 35: 565-569.

65. Barnes, A.J. Blood viscosity in diabetes mellitus. In: Lowe, G.D.O., Barbarel, J.C. \& Forbes, C.D. (eds) Clinical Aspects of Blood Viscosity and Cell Deformability. Springer Verlag, New York, 1981, pp. 105-111.

66. Seviour, P.W., Rains, S.G.H., Richmond, W. \& Elkeles, R.S. Plasma fibrinogen and macrovascular disease in noninsulin-dependent diabetes. Diabetic Med 1986, 3: 388A. 
67. Smith, E.B. Fibrinogen, fibrin and fibrin degradation products in relation to atherosclerosis. Clin Haematol 1986, 15: 355-370.

68. Letcher, R.L., Chien, S., Pickering, T.G., Sealey, J.E. \& Laragh, J.H. Direct relationship between blood pressure and blood viscosity in normal and hypertensive subjects. Role of fibrinogen and concentration. Am J Med 1981, 70: 1195-1202.

69. Letcher, R.L., Chien, S. \& Laragh, J.H. Changes in blood viscosity accompanying the response to prazosin in patients with essential HT. J Cardiovasc Pharmacol 1979, 1 (Suppl 1): S8-S20.

70. Parving, H.H. \& Hammel, E. Prognosis in diabetic nephropathy. Br Med J 1989, 299: 230-233.

71. Melbourne Diabetic Nephropathy Study Group. Comparison between perindopril and nifedipine in hypertensive and normotensive diabetic patients with microalbuminuria. Br Med J 1991, 302: 210-216.

72. Kannel, W.B. Prevalence and natural history of electrocardiographic left ventricular hypertrophy. Am J Med 1983, 75 (Suppl 3A): 4-11.

73. Messerli, F.H., Oren, S. \& Grassman, E. Left ventricular hypertrophy and antihypertensive therapy. Drugs 1988, 35 (Suppl 5): 27-33.

74. Shapiro, L.M. Specific heart disease in diabetes mellitus. $\mathrm{Br}$ Med J 1982, 284: 140-141.

75. Lundgren, H., Bjorkman, L., Keiding, P., Lundmark, S. \& Bengtssar, C. Diabetes in patients with hypertension receiving pharmacological treatment. Br Med J 1988, 297: 1512.

76. Struthers, A.D., Murphy, M.B. \& Dallery, C.T. Glucose tolerance during antihypertension therapy in patients with diabetes mellitus. Hypertension 1985, 7 (Suppl II): $\mathrm{II}_{95}-\mathrm{II}_{101}$.

77. Murphy, M.B., Lewis, R.J., Kohner, E., Schiemer, B. \& Dallery, C.T. Glucose tolerance in hypertensive patients treated with diuretics: a fourteen year follow-up. Lancet 1982, ii: $1293-1295$.

78. Skarfors, E.T., Lithell, H.O., Selinus, I., Aberg, H. Do antihypertensive drugs precipitate diabetes in predisposed men? Br Med J 1989, 298: 1147-1152.

79. Kendall, M.J. Are selective beta-adrenoreceptor blocking drugs an advantage? $J R$ Coll Physicians Lond 1981, 15: $33-40$.

80. Holm, C. Adrenergic regulation of insulin release. Acta Med Scand 1983, 672: 21-25.

81. Dzau, V.J. \& Sacks, F.M. Regulation of lipoprotein metabolism by adrenergic mechanisms. J Cardiovasc Pharmacol 1987, 10 (Suppl 9): 2-6.
82. Nash, D.T., Schonfield, G., Reeves, R.K., Black, H. \& Weidler, D.J. A double-blind trial to assess the efficacy of doxazosin, atenolol and placebo in patients with mild to moderate systemic hypertension. Am J Cardiol 1987, 59: 87G-90G.

83. Pollare, T., Litchell, H. \& Berne, C. Application of prazosin is associated with an increase of insulin sensitivity in obese patients with hypertension. Diabetologia 1988, 31: 415-420.

84. Feher, M.D., Henderson, A.D., Wadsworth, J. et al. Alphablocker therapy: a possible advance in the treatment of diabetic hypertension - results of a cross-over study of doxazosin and atenolol monotherapy in hypertensive noninsulin-dependent diabetic subjects. J Human Hypertens 1990, 4: 571-577.

85. Weidmann, P., Ferrier, C., Saxenhofer, H., Uehlinger, D.E. \& Trost, B.N. Serum lipoproteins during treatment with antihypertensive drugs. Drugs 1988, 35 (Suppl 6): 118-134.

86. Feher, M.D., Rains, S.G.H., Richmond, W. et al. Betablockers, lipoproteins and non-insulin dependent diabetes. Postgrad Med J 1988, 64: 926-930.

87. Feher, M.D., Torrens, D.J., Richmond, W., Wadsworth, J. \& Sever, P.S. Acute lipoprotein changes with atenolol therapy for hypertension in non-insulin dependent diabetes. J Human Hypertens 1988, 2: 253-255.

88. MacMahon, S.W. \& MacDonald, C.J. Antihypertensive treatment and plasma lipoprotein level: the association in data from a population study. Am J Med 1986, 80 (Suppl 2A): 20-47.

89. World Health Organisation. Arterial hypertension. Report of a WHO Expert Committee. WHO Tech Rep Service 1978, 628.

90. British Hypertension Society Working Party. Treating mild hypertension. $\mathrm{Br}$ Med J 1989, 298: 694-698.

91. The Working Group on Hypertension in Diabetes: State-응 ment on hypertension in Diabetes Mellitus; Final Report. Arch Intern Med 1987, 147: 830-842.

92. Dodson, P.M. \& Horton, R.C. The hypertension of diabetes mellitus: mechanisms and implications. $J$ Hum Hypertens 1988, 1: 249-258.

93. Parillo, M., Coulston, A., Hollenbeck, C. \& Reaven, G.M. Effect of a low fat diet on carbohydrate metabolism in patients with hypertension. Hypertension 1988, 11: 244-248. 